\title{
Path analysis of the revisit potential of an iconic tourism destination
}

\author{
Rumpapak Luekveerawattana ${ }^{1}$ and Yothin Sawangdee ${ }^{2, *}$ \\ ${ }^{1}$ Suan Sunandha Rajabhat University, Bangkok, Thailand \\ ${ }^{2}$ Institute for Population and Social Research, Mahidol University, Bangkok, Thailand
}

\begin{abstract}
This study aims to investigate factors that affect the revisit potential of a historic destination. This study has a conceptual framework that is based on theory and literature review of the sustainable tourism management. This is a quantitative study that collected data from 800 international visitors who visited two famous religious tourism sites in Bangkok, namely the reclining Buddha temple and the emerald Buddha temple. These visitors were selected through the accidental sampling method. The data were analyzed using path analysis. The study showed that interpretation positively affects revisit potential, local people negatively influence revisit potential, and process positively affects revisit potential. Interpretation, local people, and process have both direct and indirect influences on revisit potential.
\end{abstract}

\section{Introduction}

According to the United Nations World Tourism Organization (UNWTO), tourism has the potential to contribute, directly or indirectly, to sustainable development goals [1]. With the rapid expansion of international tourism due to social, economic, political and technological changes, tourism is spreading from developed countries to newly industrialized countries [2]. The tourism sector has become a significant source of domestic income worldwide; in the large part, this is due to modern efforts to remove barriers to international mobility as well as developments and cost reductions in the transport sector [3]. The UNWTO has recently re-affirmed cultural tourism as a major element of international tourism consumption, accounting for over $39 \%$ of tourism arrivals [4].

Cultural tourism is a relevant tangible and intangible asset. Many countries transform unique and valueless assets into representations of national identity [5]. Cultural tourism provides an opportunity for people to experience their culture in depth by visiting attractions as well as historical or culturally relevant places [6]. In addition, due to the selection process, cultural heritage always reflects the messages and values of modern society[7]. Countries search for and set up cultural resources as tools for generating income and improving quality of life [8]. There is more interest in artisan entrepreneurship due to its role in revitalizing economies and placing emphasis on cultural heritage and traditions [9]. Globally, many agencies, institutions and individuals involved in economic development programs have recognized the need to help developing countries preserve

\footnotetext{
*Corresponding author: rumpapak.lu@ssru.ac.th
} 
cultural resources and values. Many countries try to restore historic sites to attract overseas tourists $[10,11]$ in the interest of providing means for the social revitalization of communities and neighbourhoods.

In order to successfully develop international tourism, industry professionals need to understand the cultural differences between themselves and international tourists and also between tourists and the host society [12]. Research has addressed strategies for enticing visitors to make repeat visits [13]. Specifically, empirical research tests theories and methods in a wide variety of contexts such as tourist behavior issues, tourist satisfaction in different method, tourism motivation issues in various determinats. [14] and the concept of experience as a psychological driver in tourism [15]. Visitors apply five main sources of information, namely memory and personal sources, independent, marketing, and experiential sources [16]. It is broadly acknowledged that interactions between tourists significantly affect behavioral reactions, such as the desire to stay, satisfaction, and loyalty - all of which are important for tourism destination marketing [17]. Visitors are normally drawn to tourism destinations by mixtures of attractions, events and services offered [18]. Tourism can revive traditions of the past, boost actively cultural performances, and facilitate cross-cultural communication [19].

Tourism has become one of the most important sectors in many Asia-Pacific countries [20]. Many tourism sites managers devise ways to lure the visitors back again and again with the overarching goal of sustaining their sites and distributing cultural characteristics worldwide; however, It is a challenge for tourism site stakeholders to consider and analyze revisit potential [21]. Thailand's Bangkok is a pivotal southeast Asian city. It is home to the primary tourism hub as well as the region's airports. As a result, a large number of tourists from around the world exert considerable pressure on Bangkok's attractions. Iconic final destinations in Bangkok that are well worth a visit include Wat Phra Kaew or the Emerald Buddha, Wat Prachetuphonwimolmangkalaram (Wat Pho), which is well known from the tourist as the temple of the traditional Thai massage center (Nuad Thai) and the reclining Buddha [22]. Given the stiff competition for tourists' attention, it is easy to understand why historical destination managers try to generate and employ viable techniques for capitalizing on revisit potential. Only a limited number of works have focused on using path analysis to investigate the onsite management process and interpretation related to the revisit potential at historical destinations. This study has aimed to fill that research gap.

\section{Selective Literature Review and the Choice of Variables for the Model}

\subsection{Interpretation}

Interpretation aims to stimulate interest, promote learning, guide visitors' on appropriate behaviour for sustainable tourism, and encourage enjoyment and satisfaction [23]. In addition, interpretation helps visitors enhance their knowledge about destinations, making them more culturally sensitive and aware. Academic research has established that there are many tools to interpret about in the Baba and Nyonya tourism areas. [24].Visitors are encouraged to experience tourism resources' value by interpretation technique using [25]. A structure of interpretation was recognized comprising the major portion, the different few, and the vague plenty. Within this structure is about to convey tourism resources' value both tangible and intangible, at local and national level to the visitors [26]. Interpretation helps to reduce environmental and cultural impact. 
Anyway, all tourism transaction as transportation and activities related to hospitality may be hindrances in undertaking the environmental sustainability of tourism systems. The application of online booking and promotion, information and management systems transmission, other mode of internet-based tourism activities as ICT systems, AI and GPS that are connected to hospitality and tourism providers may help these companies decrease their environmental and cultural impact [27]. Interpretation plays an important role in the tourism industry. Considering ten value orientations and four meanings, nine groups have been identified, representing groups of millennial tourists with distinct needs. For example, while two groups fit into the popular description of young travellers inquiring only modest enjoyment, youth travelling as acted for two other groups, is strongly motivated by selftranscending values, escapism (or travellers distancing themselves through travel), and relaxation [28].

Therefore, the interpretation dimension was measured by using the following seven items: guidance material travel agencies provide to tourists is adequate for tourists to get through agencies' tourism site; easy and convenient booking systems of travel agencies; sufficient transportation modes available to the tourists to access tourism destination; the modern and specious vehicles for tourists; publicity and public relations to enhance the images of tourism sites; sufficient direct marketing methods, such as telemarketing, direct mail, and the internet; sufficient advertising media, such as television, newspapers, magazines, and media-delivered tourist information enrich tourists' knowledge of their tourism destination.

\subsection{Process}

Process refers to a series of facts that are carried out in order to achieve a particular result. There are several acts that comprise the tourism process. The following eight aspects were originated to appraise cultural tourism elements: onsite interpretation, cultural importance, physical presentation, contribution to place, prior knowledge, motivation to visit, general importance to visitors and onsite experience [29].

The key reasons to create a successful tourism destination are natural and cultural attractions, and national security and safety. This means that management process requires the success of the main acts related to destination. Tourists confirmed that imagery of their favorite mountain destinations consists mostly of functional elements. The findings showed that selecting the favorite destinations was related to destination imagery (DY) processing and destination choice [30]. Quality of experience has an indirect effect on behavioral intentions when mediated by perceived value and satisfaction [31]. For that reason, the process dimension was measured using the following four items: quality of site management, cleanliness of the destination, readiness for international tourism, and use of standard procedures.

\subsection{Local people}

Local people play a key role in supporting cultural tourism. Rustic population's attitudes towards tourism development were not inactive; rather, they experience a motive process of change in three stages. Residents should deepen their involvement in tourism projects and tourism management process [32].

However, local people' $\mathrm{s}$ attitudes toward tourism vary according to the types of benefits they receive from the industry[33].Moreover, it was found that permanent residents were significantly more aware of conserving and protecting their community's tourism resources. Local institutional community arrangements are increasingly recognized as successful mechanisms for achieving sustainable forest management [34]. 
Some scholars have proposed the use of the dwelling perspective in their analysis of tourism in order to embed local people in their cultural landscape[35]. Following that, this study's local people dimension was measured by adopting the following four items: whether local people and staffs give information precisely, whether they provide service enthusiastically, whether they possess the skill to communicate in international language, and whether they are helpful, warm, and welcoming.

\subsection{Revisit potential}

Investment in promotion and image creation is very important for repeat visits and economic sustainability of tourist destinations. Interestingly, the information sources that played the largest part in creating pre-visit images were actually sources that were outside the control of destination managers [36]. Place attachment could be a desired outcome for destination and event marketers since it is an indication of loyalty to both the event (activity) and the destination [37]. Five interrelated dimensions were deemed important to visitors' evaluations of cultural destinations. Consistent with place and destination branding literature, the significance of specific cultural brand assets is emphasized. The study described the structural relationships that were developed among assets, awareness, associations and quality, and links these with intentions to revisit [38]. Moreover, it is confirmed that through destination satisfaction, destination image predicts intent to revisit. Destination managers should try to maintain high-quality tourist shuttle service, specifically as it pertains to staff service, efficiency, punctuality, and safety [39]. In light of the above, the revisit potential dimension was measured using the following four items: tourist satisfaction, expectation and satisfaction on the tourism site, worthiness of a visit, and intent to revisit.

Based on the above theories and literature review, this study has developed a measurement model for comparison with the empirical data as shown in fig. 1.

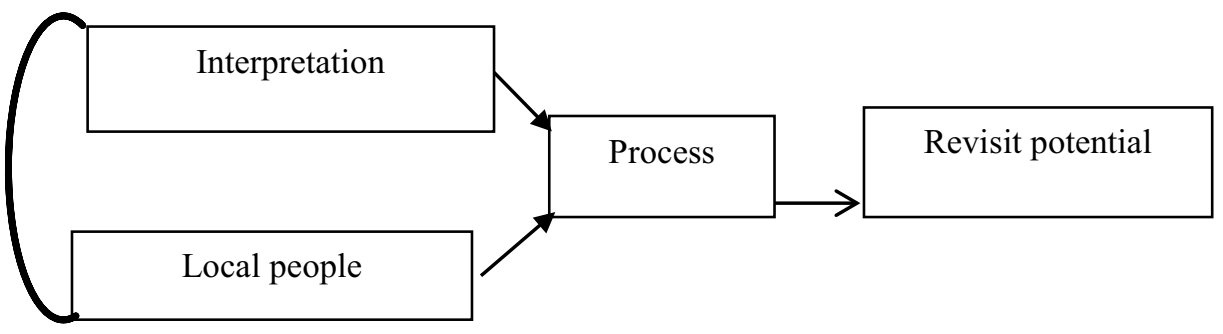

Fig. 1. Measurement model.

\subsection{Hypothesis}

Hypothesis 1: Interpretation significantly influences revisit potential Hypothesis 2: Local people significantly influence revisit potential Hypothesis 3: Process significantly influences revisit potential Hypothesis 4: Interpretation significantly influences Process Hypothesis 5: Local people significantly influence Process 


\section{Methods}

\subsection{Data Collection}

This study is a quantitative, survey-based research. According to the Association of Thai Travel Agents, there were 5,578,632 tourists in 2018. Data collected for this study were gathered using questionnaires over a 2-months period from April 1 to May 30, 2018. Questionnaires were given to tourists in crowded tourist areas such as the emerald Buddha temple and the Pho (or reclining) temple in Bangkok, Thailand.

The researcher used questionnaires to collect data from 850 Thai and international respondents. Some declined to participate with 50 people citing time constraints. Eight hundred people were willing and able to share the relevant information. Each respondent took seven to eight minutes to complete the questionnaire. Accidental sampling was used. The researchers stood near the target locations from 7.30 a.m. to 16.00 p.m. with a 2-hour break at noon. There were five assistant researchers standing at the temple to collect data. This required permission from each tourist/visitor, particularly if they came with a tour group, in which case the tour leader's permission was sought.

The researcher used path analysis to determine correlations between independent and dependent variables in the context of direct and indirect effects. Research tools for this study included structural questionnaires, which were divided into two portions. The first portion was about social and population data while the second portion was about the effect of independent and dependent variables. Responses related to all variables were on a 5point Likert-type scale.

\subsection{Data Analysis}

This study investigates the relationship between the variables in path and the four dimensions, namely interpretation, local people, process, and revisit potential. All questionnaire items were scored on 5-point Likert scale (where $1=$ strongly disagree and 5 $=$ strongly agree). The scale's Cronbach's alpha was 0.79 . Structural equation modeling (SEM) was utilized to test the effects of the four dimensions.

\section{Results and Discussion}

\subsection{Respondent Profile}

A little more than half $(60.8 \%)$ of the respondents were females while the remainder consisted of males. The majority $(62.0 \%)$ were within the age range 18 to 30 years old; $32.5 \%$ were between 31 and 43 years old and about $5.5 \%$ were 44 years old and over. Most of the respondents $(59.5 \%)$ had education below the level of a bachelor's degree while around $34.6 \%$ held bachelor's degrees; the remainder of the respondents $(5.9 \%)$ had education that was above the level of a bachelor's degree. Students comprised $45.3 \%$ of the respondent group; about $14.6 \%$ and $14.4 \%$ were businessmen and government officers, respectively, while the remainder consisted of employees and others. A little less than half $(42.5 \%)$ had income that were below USD 490 whereas about $32.1 \%$ had income between USD 491 and 976 . Visitors were single (66.9\%) and married (23.9\%).

More than half of the visitors stayed at hotels $(46.9 \%)$ while some stayed in their own houses $(26.2 \%)$; the remainder stayed at hostels, their relative's houses, and resorts. Most $(66.6 \%)$ indicated that they would come back to the tourism site. 
The majority of visitors were Thai (43.1\%) followed by Chinese (30.4\%); the remainder consisted of Asians, Europeans, Africans, North Americans, Australians, and others. Some visitors come alone (33.7\%) while others come with friends $(27.5 \%)$; the rest travelled with family (26\%). Respondents had expenses within the range of USD 165 to 327 (40.3\%) or less than USD 164 (34.3\%). Table 1 represents these respondent profile characteristics. An attempt was made to check whether the data set was free from the issue of multicollinearity by testing the relationship between variables. Tests confirmed that there was no multicollinearity because the correlation of the variables is less than $0.80(\mathrm{r}<0.80)$. Therefore, it was proper to test structural equation modelling as shown in Table 1.

Table 1. Correlations between dependent variable and independent variable.

\begin{tabular}{|l|c|c|c|c|}
\hline & Interpretation & Local people & Process & Revisit potential \\
\hline Interpretation & & .513 & .478 & .409 \\
\hline Local people & & & .539 & .342 \\
\hline Process & & & & .562 \\
\hline Revisit potential & & & & \\
\hline
\end{tabular}

Diagram 2 indicates that process is directly affected by interpretation and local people. We regressed process on these two causal variables and obtained $\mathrm{R} 2=.35$. The diagram also indicates that revisit potential is directly and indirectly affected by interpretation, local people, and process. We regressed process on these three causal variables and obtained R2 $=.34$.

The diagram suggested that interpretation and local people were highly related (51\%). It follows that interpretation and local people should be arranged by a good process in order to yield a high rate of revisit potential. Only local people were not workable in term of increasing the chances of revisit. Therefore, process is the moderated variable that most strongly affects revisit potential [40-41]

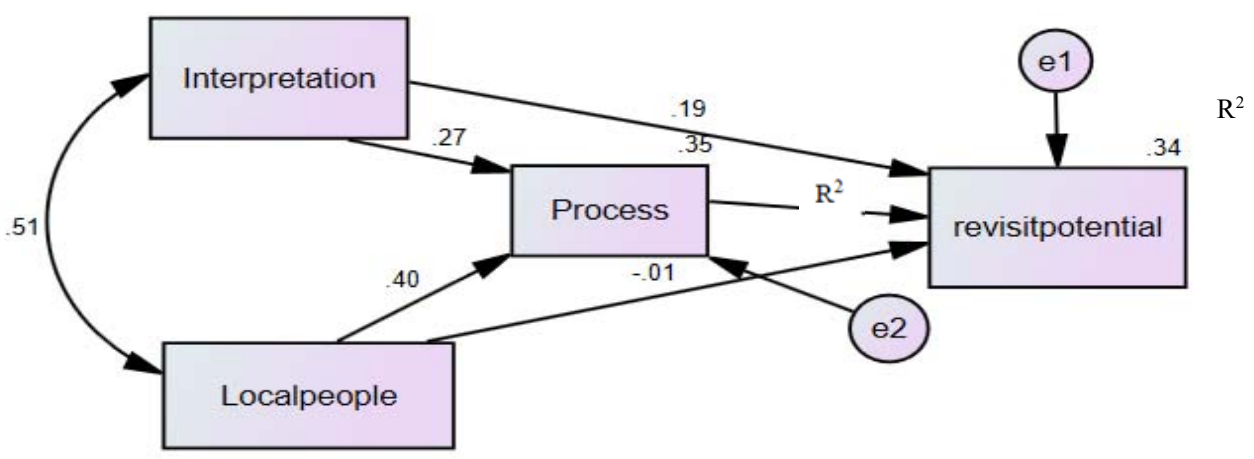

Fig. 2. Path analysis.

Table 2. Model fit of the measurement model.

\begin{tabular}{|l|c|c|c|c|c|c|}
\hline Model fit Criteria & CFI & GFI & NFI & IFI & CMIN/DF & RMR \\
\hline Indicator value & $>.90$ & $>.90$ & $>.90$ & $>.90$ & $<3$ & $<.08$ \\
\hline Empirical data & 1 & 1 & 1 & 1 & .00 & .00 \\
\hline
\end{tabular}

A model is regarded as acceptable if the normed fit index (NFI) exceeds .90 [42]. The goodness of fit index exceeds .90 , the comparative fit Index exceeds .93[42], the relative chi-square is less than 2 or 3[43], RMS is less than .08 [44] and ideally less than .05 [45]. Alternatively, the upper confidence interval of the RMS should not exceed 08 [46]. 
It was found that interpretation affected process $(\beta=.27, \mathrm{p}<.001)$, local people affected process $(\beta=.40, \mathrm{p}<.001)$, interpretation affected revisit potential $(\beta=.19, \mathrm{p}<$ $.001)$, and process affected revisit potential $(\beta=.48, \mathrm{p}<.001)$ as Diagram 2 and Table 2.

Table 3. Standardized Regression Weights.

\begin{tabular}{|l|c|c|c|c|c|}
\hline Variables & Estimate* & S.E. & $\begin{array}{c}\text { C.R. } \\
\text { t-value }\end{array}$ & P-value & $\begin{array}{c}\text { Statistically } \\
\text { significant }\end{array}$ \\
\hline Process $<---$ Interpretation & .27 & .03 & 8.20 & $* * *$ & yes \\
\hline Process $<---$ Localpeople & .40 & .02 & 11.99 & $* * *$ & yes \\
\hline revisitpotential<---Interpretation & .19 & .04 & 5.35 & $* * *$ & yes \\
\hline revisitpotential $<---$ Localpeople & -.01 & .04 & -.35 & .73 & no \\
\hline revisitpotential<---Process & .48 & .05 & 13.52 & $* * *$ & yes \\
*** $<<.001$
\end{tabular}

Interpretation and local people directly affect process at .27 and .40 , respectively. Interpretation, local people and process have both indirect and direct effects on revisit potential. Interpretation and local people indirectly affect revisit potential at .14 and .19, respectively. Likewise, interpretation and process directly affect revisit potential at .19 and .48 , severally. Furthermore, interpretation, local people, and process generate a total effect on revisit potential at $.32, .18$, and .48 separately as table 3 and table 4 .

Table 4. Standardized Total Effects and standardized Indirect Effects.

\begin{tabular}{|l|l|c|c|c|}
\hline \multirow{2}{*}{$\begin{array}{c}\text { Dependent } \\
\text { variable }\end{array}$} & \multirow{2}{*}{ Effects } & \multicolumn{3}{|c|}{ Predicted variable } \\
\cline { 3 - 5 } & & Interpretation & Local people & Process \\
\hline \multirow{3}{*}{ process } & Direct Effect & .27 & .40 & .00 \\
& Indirect Effect & .00 & .00 & .00 \\
& Total Effect & .27 & .40 & .00 \\
\hline \multirow{2}{*}{ Revisit } & Direct Effect & .19 & -.01 & .48 \\
potential & Indirect Effect & .13 & .19 & .00 \\
& Total Effect & .32 & .18 & .48 \\
\hline
\end{tabular}

\subsection{Discussion}

In support of Hypothesis 1, the findings have shown that interpretation exerts a significant positive influence on revisit potential, meaning that interpretation plays a part in motivating visitors to travel to destinations again. Interpretation encourages visitors to increase their knowledge as well as the joyful feelings that lead to more meaningful and transformative experiences through geo tourists' engagement with the landform's cultural landscape[47].

The findings also harmonized with research results that have shown that personal and non-personal interpretations account for differences in the Baba and Nyonya tourism areas. It was found that before the treatment group read the ten postcards, their knowledge was minimal; however, after they read the postcards and engaged in self-guiding interpretation, their knowledge was significantly different at .05 [48].

With regard to Hypothesis 2, the study has expressed that local people do not significantly influence revisit potential. This suggests that there is no direct relationship between local people and revisit potential. However, local people participate in visitor stimulation through the process of destination management.

Referencing Hypothesis 3, process significantly influences revisit potential. Process plays a key role in encouraging visitors' decision to visit. According to article research that pointed out the process of appropriate visitor management, this is an integral part of sound tourism management. It is important to create enjoyable visitor experiences in the hope that visitors will appreciate the value of the site[49]. 
With regard to Hypothesis 4, interpretation significantly influences process. It was indicated that interpretation promotes the efficiency of the destination management process. Interpretation creates place attachment and tempts visitors to revisit; this reflects the thoughts that were expressed in an academic article on place attachment mediating the relationship between destination image and revisit intention [50].

Finally, with regard to Hypothesis 5, local people significantly influence process. It was indicated that local people are indispensable to the tourism management process as research findings have suggested that residents' inclusion in benefit-sharing mechanisms is associated with a reduced perceived gap between the importance and performance of ecotourism [51]. In conclusion, many historical destination stakeholders should concentrate on process in tourism management with attention to the quality of site management, the cleanliness of the destination, readiness for international tourism, and the use of standard procedures since these factors affect visitor's impression and experience [52] as well as whether they will revisit the historical destination.

As shown in Diagram 2 , the vital component in maintaining visitors' revisit rates is management process. It was confirmed that through a perfect management process, interpretation and local people are workable elements. Therefore, a high-quality management process leads to high revisit potential.

\section{Acknowledgements}

We would like to express my sincere thanks to Suan Sunandha of Rajabhat University for providing us a research scholarship and research facilities so that we could accomplish our research.

\section{References}

1. J. Vanegas et al., Tourism and Hospitality Management 26(1), 49-67 (2020)

2. H. Song et al., Annals of Tourism Research 75, 338-362 (2019)

3. Y. Bayar, B. Yener, European Journal of Tourism Research 21, 23-32 (2018)

4. G. Richards, Journal of Hospitality and Tourism Management 36, 12-21 (2018)

5. J. Prada-Trigo et al., Journal of Tourism, Culture and Territorial Development 7(14), 17-37 (2016)

6. V.T. Hafstein, Cultural Heritage. A Companion to Folklore, 500-519 (2012)

7. P. Battilani et al., Journal of Sustainable Tourism 26(8), 1-20 (2018)

8. A. Nicely, R. Ghazali, International Journal of Hospitality and Tourism Administration 18(2), 171-194 (2017)

9. V. Ratten et al., International Journal of Entrepreneurial Behaviour and Research 25(4), 582-591 (2019)

10. G. Adam, J. Scott, South East Asian Hospitality Management Studies 7(3), 2-13 (2007)

11. S. Bhattacharya, R. Kumar, Journal of Modelling in Management 12(4), 583-602 (2017)

12. F. Meng, International Journal of Culture, Tourism and Hospitality Research 4(4), 340-351 (2010)

13. R. Cui et al., Annals of Tourism Research 102771 (2019)

14. S. Wijaya et al., Tourism, Culture and Communication 17(2), 79-81 (2017) 
15. L. Andreu, M. Kozak, International Journal of Culture, Tourism and Hospitality Research (2009)

16. R. Siri et al., Tourismos 7(1), 61-79 (2012)

17. H. Sun et al., Sustainability 11(15), 4030 (2019)

18. I. Önder, E. Marchiori, Tourism Management Perspectives 21, 42-53. (2017)

19. J. Jafari, Hosts and Guests Revisited: Tourism Issues of the 21st Century (2001)

20. C. Guzeller, N. Celiker, Asia Pacific Journal of Tourism Research 24(1), 108-120 (2019)

21. K. Kasemsap, Global Business Expansion: Concepts, Methodologies, Tools, and Appl., 1191-1221 (2018)

22. A. Bhati, P. Pearce, Tourism Management 63, 15-30 (2017)

23. G. Moscardo, International Journal of Culture, Tourism, and Hospitality Research 11(2), 111-124 (2017)

24. U. Muneenam et al. Kasetsart Journal of Social Sciences 38(3), 251-258 (2017)

25. A. Heywood, N. Zwar, Journal of Travel Medicine 25(1), 1-8 (2018)

26. X. Yu, H. Xu, Journal of Destination Marketing and Management 13, 39-50 (2019)

27. M. Ruiz-Molina, B. Moliner-Velázquez, Management of Environmental Quality: An International Journal 21(4), 464-476 (2010)

28. E. Cavagnaro et al., Journal of Tourism Futures 4(1), 31-42 (2018)

29. A. Araújo et al., European Journal of Tourism Research 22, 151-165 (2018)

30. C. Chen, F. Chen, Tourism Management 31(1), 29-35 (2010)

31. X. L. Ma et al., Tourism Management 76, 103957 (2020)

32. B. Sharma, P. Dyer, Benchmarking 16(3), 351-371 (2009)

33. S. Nhem, Y. Lee, Forest Policy and Economics 106 (2019)

34. S. Prince, Tourist Studies 18(1), 63-82 (2018)

35. J. Cave et al., International Journal of Culture, Tourism and Hospitality Research 6(2), 95-113 (2012)

36. K. Kaplanidou et al., Journal of Sport Management 26, 237-248 (2012)

37. J. Kehagias, Journal of Destination Marketing \& Management 3, 2-10 (2014)

38. L. T. Loi et al., Journal of Hospitality and Tourism Management 32, 115-123 (2017)

39. H. T. Van et al., Journal of International Studies 10(4), 109-118 (2017)

40. M. Nuijten et al., Tourism Culture \& Communication 16(3), 123-135 (2016)

41. B. Byrne, Measuring Instrument 1(1), 55-86 (2001)

42. E. Andreeva et al., Actual Problems of Economics 183(9), 220-227 (2016)

43. M. Browne, R. Cudeck, Multivariate Behavioral Research 25(2), 173-180 (1990)

44. L. Hu, P. Bentler, Psychological Methods 3(4), 424-453 (1998)

45. J. Aquino et al. Tourism, Culture and Communication 12(1), 5-18 (2012)

46. D. Ushakov et al., Geojournal of Tourism and Geosites 27(4), 1429-1438 (2019)

47. S. Kim et al. Asia Pacific Journal of Tourism Research 22(1), 49-63 (2017)

48. K. Birendra et al., Asia Pacific Journal of Tourism Research 23(6), 560-572 (2018)

49. M. Ahn et al., Tourism Culture \& Communication 18(4), 241-250 (2018) 